\title{
The physiological effects of Shinrin-yoku (taking in the forest atmosphere or forest bathing): evidence from field experiments in 24 forests across Japan
}

\author{
Bum Jin Park · Yuko Tsunetsugu • Tamami Kasetani • \\ Takahide Kagawa · Yoshifumi Miyazaki
}

Received: 18 July 2008/Accepted: 6 April 2009/Published online: 2 May 2009

(C) The Japanese Society for Hygiene 2009

\begin{abstract}
This paper reviews previous research on the physiological effects of Shinrin-yoku (taking in the forest atmosphere or forest bathing), and presents new results from field experiments conducted in 24 forests across Japan. The term Shinrin-yoku was coined by the Japanese Ministry of Agriculture, Forestry, and Fisheries in 1982, and can be defined as making contact with and taking in the atmosphere of the forest. In order to clarify the physiological effects of Shinrin-yoku, we conducted field experiments in 24 forests across Japan. In each experiment, 12 subjects ( 280 total; ages $21.7 \pm 1.5$ year) walked in and viewed a forest or city area. On the first day, six subjects were sent to a forest area, and the others to a city area. On the second day, each group was sent to the other area as a cross-check. Salivary cortisol, blood pressure, pulse rate, and heart rate variability were used as indices. These indices were measured in the morning at the accommodation facility before breakfast and also both before and after the walking (for $16 \pm 5 \mathrm{~min}$ ) and viewing (for $14 \pm 2 \mathrm{~min}$ ). The $\mathrm{R}-\mathrm{R}$ interval was also measured during the walking and viewing periods. The results show that forest environments promote lower concentrations of cortisol, lower pulse rate, lower blood pressure, greater
\end{abstract}

\section{B. J. Park $(\bowtie) \cdot$ Y. Miyazaki}

Center for Environment, Health and Field Sciences,

Chiba University, Kashiwa-no-ha 6-2-1,

Kashiwa, Chiba 277-0882, Japan

e-mail: bjpark@faculty.chiba-u.jp

Y. Tsunetsugu $\cdot$ T. Kagawa

Forestry and Forest Products Research Institute,

1 Matsunosato, Tsukuba, Ibaraki 305-8687, Japan

\section{T. Kasetani}

Chiba Prefectural Agriculture and Forestry

Research Center Forestry Research Institute,

1887-1 Haniya, Sammu, Chiba 289-1223, Japan parasympathetic nerve activity, and lower sympathetic nerve activity than do city environments. These results will contribute to the development of a research field dedicated to forest medicine, which may be used as a strategy for preventive medicine.

Keywords Therapeutic effects of forest - Heart rate variability $\cdot$ Salivary cortisol $\cdot$ Blood pressure $\cdot$ Pulse rate

\section{Introduction}

The growing interest in environmental stress has been accompanied by a rapid accumulation of evidence indicating that environment can elicit substantial stress in people living in urban environments [1]. Furthermore, it is broadly conceived that the natural environment can enhance human health [2]. There have been several questionnaire studies on the psychological effects of forest environments. A previous study found an enhancement of positive emotions among subjects who were shown pictures of natural environments [3-6]. Moreover, other studies have also found that forest environments improve the psychological wellbeing of people [7-12].

The term Shinrin-yoku (taking in the forest atmosphere or forest bathing) was coined by the Japanese Ministry of Agriculture, Forestry, and Fisheries in 1982. It can be defined as making contact with and taking in the atmosphere of the forest: a process intended to improve an individual's state of mental and physical relaxation [13]. Shinrin-yoku is considered to be the most widespread activity associated with forest and human health.

Nowadays, there is considerable interest in stress control and relaxation. Further, the field of medical science has always favored evidence-based medicine (EBM); this 
emphasizes the importance of scientific evidence in medical practice. With improved measurement techniques, the relaxation effect induced by forest settings can be clarified in a field test by measuring the changes induced in physiological parameters such as salivary cortisol, pulse rate, blood pressure, and heart rate variability (HRV).

With this social background, the Association of Therapeutic Effects of Forests was established in Japan in 2004, with the purpose of conducting a Therapeutic Effects of Forests project in Japan. At the European level, similar efforts were made through COST Action E39 on forest and human health from 2004 to 2008 [14], and on the global level, the International Union of Forest Research Organizations (IUFRO) launched a new taskforce on forests and human health in Finland in 2007 with the purpose of fostering crossdisciplinary dialogue between the different researchers in this field, especially forestry and health professionals.

As part of this effort, the Japanese Society of Forest Medicine was established in 2007 under the Japanese Society for Hygiene, with the purpose of promoting research in the field of forest medicine, including the effects of forest bathing trips and the therapeutic effects of forests on human health. At the same time, several field studies on the physiological effects of the natural environment were carried out [13, 15-19].

In this paper, we review selected field studies performed on the physiological effects of Shinrin-yoku and a study dealing with the relationship between its psychological effects and physical environmental factors. In addition, we report new results from field experiments conducted in 24 forests across Japan.

\section{Field methods}

Subjects and study sites

We conducted physiological experiments in 24 areas from 2005 to 2006 in Japan. In each experiment, 12 normal male university students (280 in total; ages $21.7 \pm 1.5$ years) participated as subjects; none reported a history of physical or psychiatric disorders. The study was performed under the regulations of the Institutional Ethical Committee of the Forestry and Forest Products Research Institute in Japan. On the day before the experiments, subjects were fully informed of the aims and procedures of the experiment and their informed consent was obtained.

\section{Physiological measurements}

Seven physiological parameters were analyzed in the present study (Table 1). For the measurement of salivary cortisol concentration, saliva was collected by holding two pieces of absorbent cotton in the mouth for 2 min and using a saliva collection tube (no. 51.1534, Sarstedt, Numbrecht, Germany). On collection, the tube was sealed with tape and immediately stored, refrigerated, and frozen; it was later analyzed for cortisol concentration (SRL, Inc., Japan). Heart rate variability (HRV) was analyzed for the periods between consecutive $\mathrm{R}$ waves in the electrocardiogram ( $\mathrm{R}-$ $\mathrm{R}$ intervals) measured by a portable electrocardiograph (AC-301A, GMS Corporation). The power levels of the high-frequency (HF; $0.15-0.4 \mathrm{~Hz})$ and low-frequency components (LF; 0.04-0.15 Hz) were calculated [20] every minute by the maximum-entropy method (Mem-Calc, GMS Ltd. [21]). The HF power is considered to reflect parasympathetic nervous activity [22]. Furthermore, the power ratios $\mathrm{HF} / \mathrm{LF}$ and $\mathrm{LF} /(\mathrm{LF}+\mathrm{HF})$ were determined to reflect the sympathetic nervous activity [23]. Systolic blood pressure, diastolic blood pressure, and pulse rate were measured by a digital blood pressure monitor using oscillometric methods (HEM1000, Omron, Japan) on the right upper arm.

\section{Psychological measurements}

The Profile of Mood States (POMS) was used to gauge the psychological response [24]. The POMS consists of 30 adjectives rated on a $0-4$ scale that can be consolidated into the following six effective dimensions: $\mathrm{T}-\mathrm{A}$ (tension and anxiety), D (depression and dejection), A-H (anger and hostility), F (fatigue), $\mathrm{C}$ (confusion), and $\mathrm{V}$ (vigor). Because of its responsiveness, the POMS have been widely used in the assessment of mood changes resulting from a variety of interventions. For the Japanese subjects, the Japanese edition of the POMS was used.

\section{Physical environmental factors}

In the physical experiment, the temperature and relative humidity, radiant heat, wind speed, predicted mean vote (PMV), and predicted percentage dissatisfied (PPD) were measured using a portable amenity meter (AM-101, Kyoto Electronics Manufacturing Co. Ltd., Japan) at each study site. In addition, atmospheric pressure (Kestrel 4000, Nielsen-Kellerman, Japan) was also measured at some locations. Relative illumination was calculated from photos of the sky captured by a digital camera (Coolpix 4500, Nikon, Japan) equipped with a fisheye lens (FC-E8, Nikon, Japan).

\section{Experimental design}

After being given an orientation to the experiment on the day before the first day of experimentation, the subjects visited and previewed the forest and city study sites. Next, 
test measurements of all the physiological indexes and subjective feelings were conducted at the accommodation facility. In order to control the background environmental conditions, identical, separate rooms were prepared as lodgings for each subject and identical meals were served during the experiments.

The subjects were randomly divided into two groups. On the first day of the experiments, six subjects were sent to a forest site, and the other six subjects to a city site. On the second day, the subjects were sent to the other type of site as a cross-check. The first measurement was taken in the early morning at the accommodations before breakfast. After the first measurement, subjects were sent to either a forest or city site. It took almost the same amount of time to reach both the forest and city sites from the accommodations. As shown in Fig. 1, upon arrival at the given site, the subjects were seated on chairs and viewed the landscape (for $14 \pm 2 \mathrm{~min}$ ). They also walked around the given site (for $16 \pm 5 \mathrm{~min})$. The second and third measurements were taken before and after this walking. The fourth and fifth measurements were taken before and after the viewing. These measurements were taken for one person at a time. In addition to these five measurements, the $\mathrm{R}-\mathrm{R}$ interval was measured continuously during the walking and viewing exercises at the given site. The HRV was calculated once a minute using the $\mathrm{R}-\mathrm{R}$ interval data. The exercise loads

Table 1 Measured physiological parameters and subjective evaluation

\begin{tabular}{|c|c|}
\hline \multirow[t]{4}{*}{$\begin{array}{l}\text { Autonomic nervous } \\
\text { activity }\end{array}$} & $\begin{array}{l}\text { Pulse rate, systolic blood pressure, diastolic } \\
\text { blood pressure }\end{array}$ \\
\hline & Heart rate variability (HRV) \\
\hline & $\begin{array}{l}\text { HF component (parasympathetic nervous } \\
\text { activity) }\end{array}$ \\
\hline & $\begin{array}{l}\mathrm{LF} / \mathrm{HF} \text { or } \mathrm{LF} /(\mathrm{LF}+\mathrm{HF}) \text { (sympathetic } \\
\text { nervous activity) }\end{array}$ \\
\hline $\begin{array}{l}\text { Endocrine system } \\
\text { activity }\end{array}$ & Salivary cortisol concentration \\
\hline $\begin{array}{l}\text { Immune system } \\
\text { activity }\end{array}$ & Salivary immunoglobulin A concentration \\
\hline
\end{tabular}

during the walking exercise in the forest and city sites were estimated with an activity monitor (AC-301A, GMS, Japan); there was no difference in exercise load between walking in a forest site and walking in a city site.

The consumption of alcohol and tobacco was prohibited and caffeine consumption was controlled.

\section{Review of field studies performed on the physiological effects of Shinrin-yoku in Japan}

We searched the major journals on medical science, physiological anthropology, and environmental science for reports on field studies on the physiological effects of Shinrin-yoku in Japan. Only articles presenting evidence of the relaxing effects related to Shinrin-yoku have been reviewed in this paper. Table 2 presents a summary of the reviewed papers.

An early study by Ohtsuka et al. [25] showed that blood glucose levels in diabetic patients decrease when they walk in a forest for 3 or $6 \mathrm{~km}$, depending on their individual physical ability. By the middle of the decade in which the above-mentioned study was performed, research on the physiological effects of Shinrin-yoku began in earnest, using improved technologies for measuring physiological indicators. These studies used a wide range of physiological indices such as salivary cortisol, pulse rate, blood pressure, and HRV. Moreover, the experiments were designed with full consideration for cross-checks and control stimuli. The studies showed that viewing forest landscapes and walking in forest settings leads to lower concentrations of cortisol, lower pulse rate, lower blood pressure, enhanced HF component of the HRV, and lower $\mathrm{LF} / \mathrm{HF}$ [or LF/(LF $+\mathrm{HF})$ ]. In particular, Park et al. [13] showed that forest environments can lower the absolute value of the total hemoglobin concentration $(\mathrm{t}-\mathrm{Hb})$, an index of cerebral activity, in the left prefrontal area of the brain. The absolute value of hemoglobin concentration had never previously been measured in the field.
Fig. 1 Forest viewing and walking
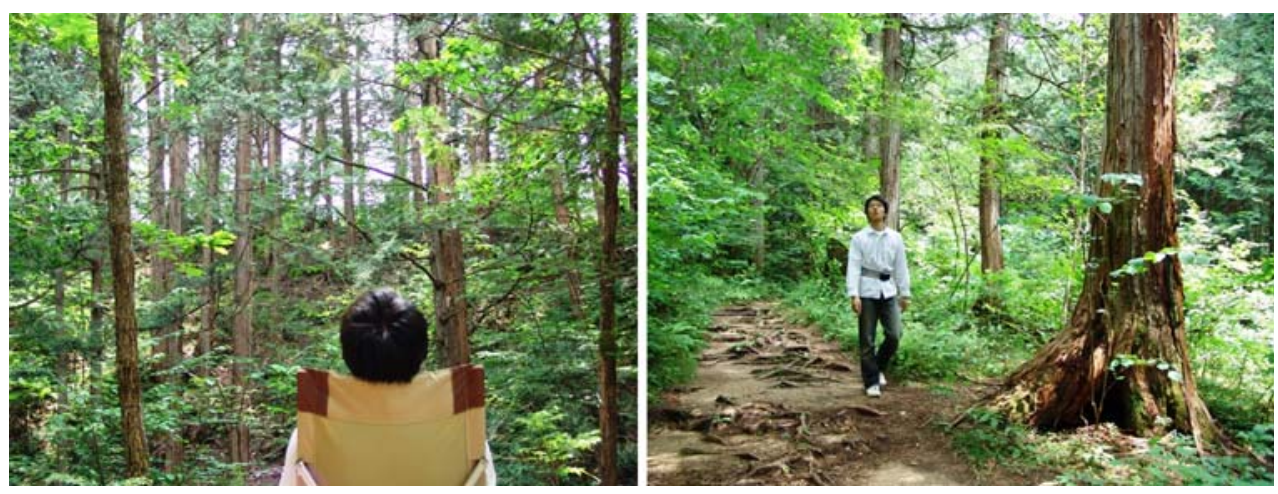
Though these studies focused on short-span exposures to stimuli (approximately $15 \mathrm{~min}$ of viewing and approximately 15 min of walking), the results strongly supported that participating in Shinrin-yoku activity could effectively relax the human body.

\section{Results of a physiological experiment in 24 forests across Japan}

Figure 2 shows the average cortisol concentration in the saliva. Salivary cortisol was significantly lower in the forest area (13.4\% decrease after the viewing; $15.8 \%$ decrease after the walking). Moreover, the average pulse rate was significantly lower (Fig. 3) in the forest area
(6.0\% decrease after viewing; $3.9 \%$ decrease after walking). Figure 4 shows that the average systolic blood pressure was significantly lower in the forest setting $(1.7 \%$ decrease after viewing; $1.9 \%$ decrease after walking). Figure 5 shows similar results for the average diastolic blood pressure (1.6\% decrease after viewing; $2.1 \%$ decrease after walking). The average power of the HF components of the HRV, which is related to parasympathetic nervous activity, increases when we feel relaxed. This value was significantly enhanced in the forest settings (56.1\% enhancement after viewing; $102.0 \%$ enhancement after walking; Fig. 6). The average $\mathrm{LF} / \mathrm{HF}$ ratio of the HRV, which is related to sympathetic nervous activity, increases when we feel stress. This value decreased when the subjects were walking in or viewing a forest $(18.0 \%$

Table 2 Findings from the literature review of physiological effects of Shinrin-yoku

\begin{tabular}{|c|c|c|}
\hline Authors & Stimuli versus control & Results of Shinrin-yoku \\
\hline Park et al. (2008) [17] & FV versus UV & $\begin{array}{l}\text { Decreased PR and SC } \\
\text { Enhanced HF }\end{array}$ \\
\hline Tsunetsugu et al. (2007) [19] & FW versus $\mathrm{UW}$ or FV versus $\mathrm{UV}$ & $\begin{array}{l}\text { Decreased PR, SBP, DBP, SC, and LF/(LF + HF) } \\
\text { Enhanced HF }\end{array}$ \\
\hline Park et al. (2007) [13] & FW versus $\mathrm{UW}$ or FV versus $\mathrm{UV}$ & Decreased SC and TH \\
\hline Furuhashi et al. (2007) [40] & FW versus $\mathrm{UW}$ or FV versus $\mathrm{UV}$ & $\begin{array}{l}\text { Decreased PR, SBP, DBP, SC, and LF/(LF + HF) } \\
\text { Enhanced HF }\end{array}$ \\
\hline Tsunetsugu et al. (2006) [18] & FW versus $\mathrm{UW}$ or FV versus $\mathrm{UV}$ & Decreased SC and $\operatorname{Ig} \mathrm{A}$ \\
\hline Park et al. (2006a) [15] & FW versus $\mathrm{UW}$ or FV versus UV & $\begin{array}{l}\text { Decreased LF/(LF + HF) } \\
\text { Enhanced HF }\end{array}$ \\
\hline Park et al. (2006b) [16] & FW versus $\mathrm{UW}$ or FV versus $\mathrm{UV}$ & Decreased SC and $\operatorname{IgA}$ \\
\hline Yamaguchi et al. (2006) [41] & FV versus $\mathrm{UV}$ or FV versus UV & Decreased SAA \\
\hline Ohtsuka et al. (1998) [25] & FW versus Non FW & Decreased BG \\
\hline
\end{tabular}

$\mathrm{HF}, \mathrm{HF}$ of $\mathrm{HRV}$; LF/(LF + HF), LF/(LF + HF) of HRV; LF/HF, LF/HF of HRV

$P R$ pulse rate, $S B P$ systolic blood pressure, $D B P$ diastolic blood pressure, $S C$ salivary cortisol, $I g A$ salivary immunoglobulin A concentration, $S A A$ salivary amylase activity, $B G$ blood glucose, $T H$ total hemoglobin concentration in prefrontal areas, $F W$ forest walking group, $F V$ forest viewing group, $U W$ urban walking group, $U V$ urban viewing group

Fig. 2 Change in salivary cortisol concentration after forest viewing and walking. Mean \pm standard deviation (SD); ** $p<0.01 ; p$-value by $t$ test
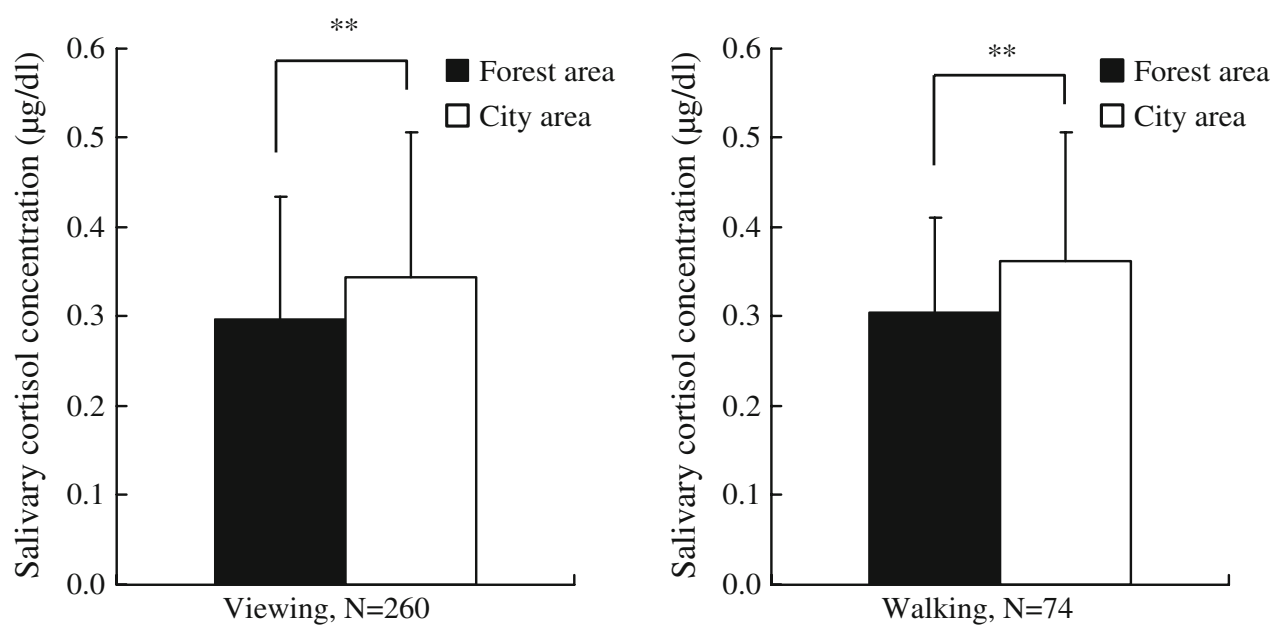
Fig. 3 Change in pulse rate after forest viewing and walking. Mean $\pm \mathrm{SD}$;

** $p<0.01 ; p$ value by $t$ test

Fig. 4 Change in systolic blood pressure after forest viewing and walking. Mean $\pm \mathrm{SD}$; $* * p<0.01 ; * p<0.05$; $p$ value by $t$ test
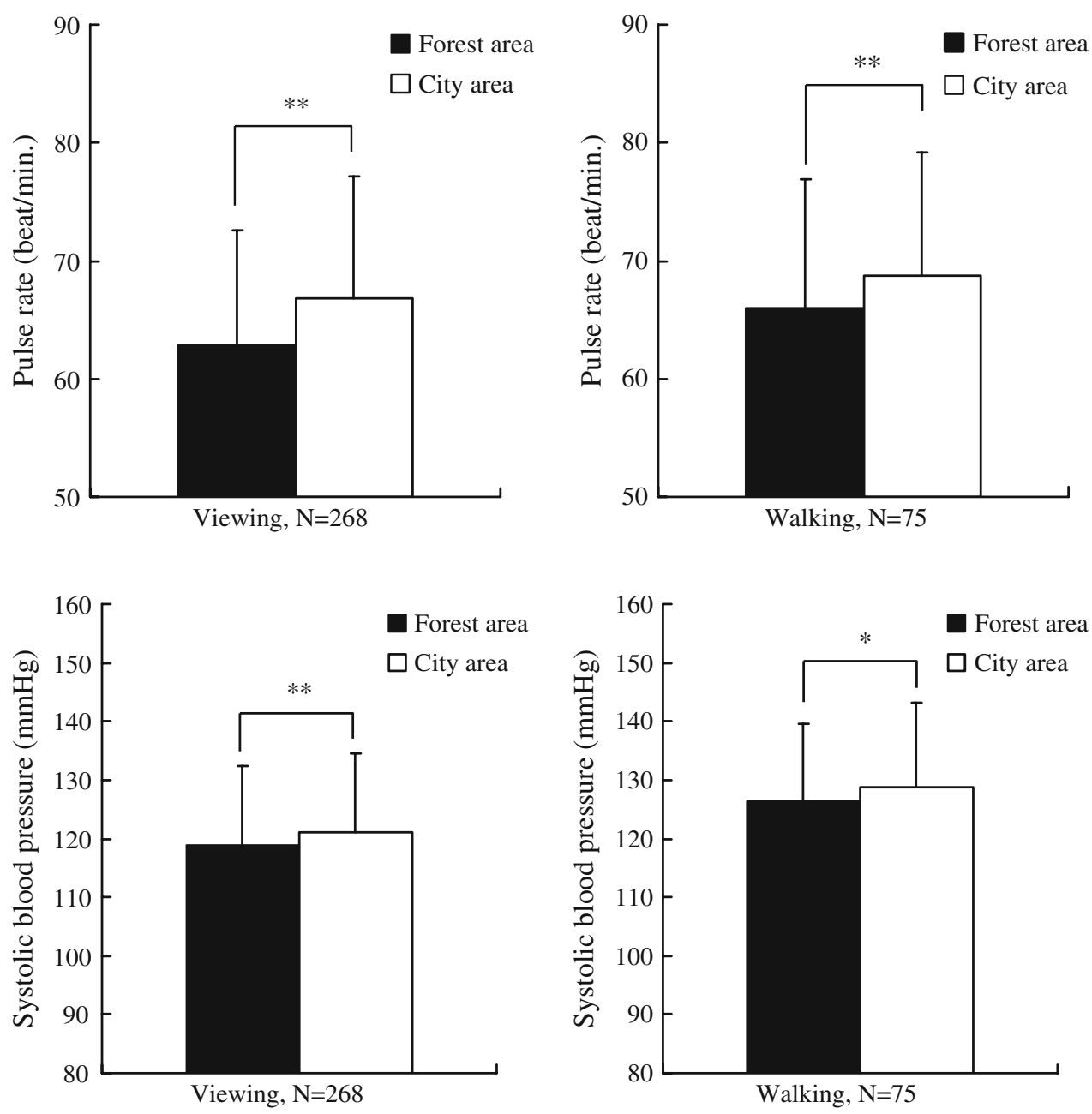

Fig. 5 Change in diastolic blood pressure after forest viewing and walking. Mean $\pm \mathrm{SD} ; * p<0.05$; $p$ value by $t$ test

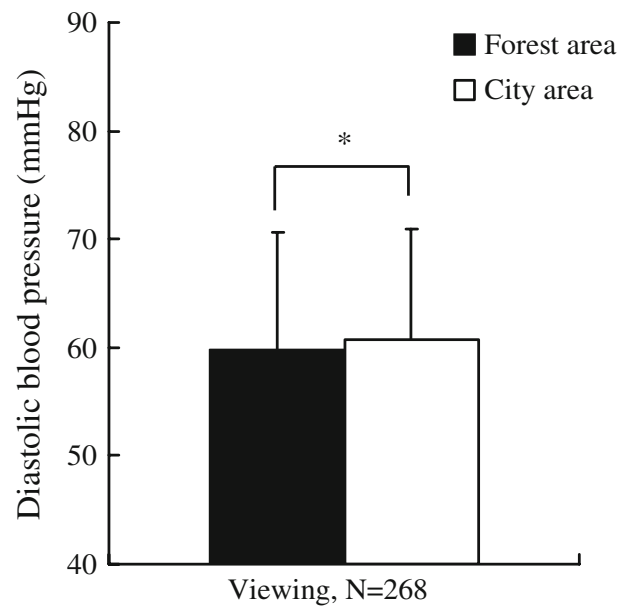

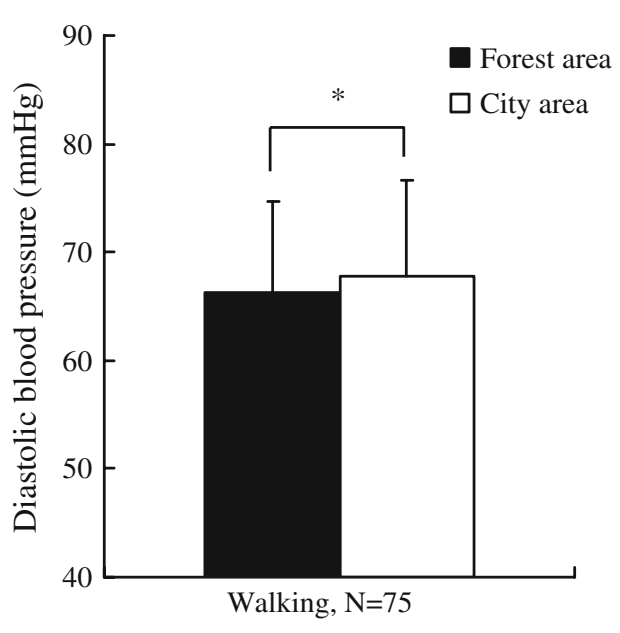

decrease after viewing; $19.4 \%$ decrease after walking; Fig. 7).

Overall, the results show that viewing forest landscapes leads to lower concentrations of cortisol, lower pulse rate, lower blood pressure, enhanced HF components of HRV, and lower LF/HF. These results strongly support the findings of indoor research using heart rate and blood pressure on the effects of viewing a forest scene on recovery from stress [1,26-28]. The effect of walking in a forest setting is the same as that of viewing a forest setting. This result corroborates Hartig et al.'s finding [27] that walking in a nature reserve initially fosters blood pressure 
Fig. 6 Change in HF power of HRV upon forest viewing and walking. Mean $\pm \mathrm{SE}$; $* * p<0.01 ; * p<0.05$; $p$ value by $t$ test
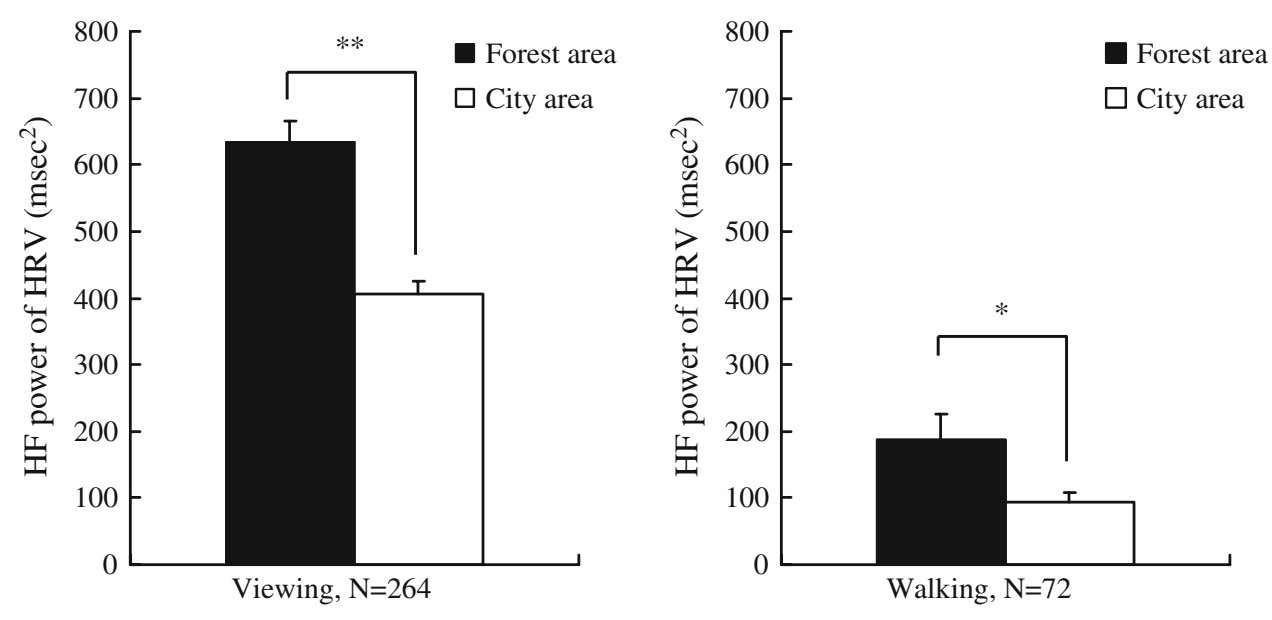

Fig. 7 Change in LF/HF of HRV upon forest viewing and walking. Mean $\pm \mathrm{SE}$; $* * p<0.01 ; * p<0.05$; $p$ value by $t$ test

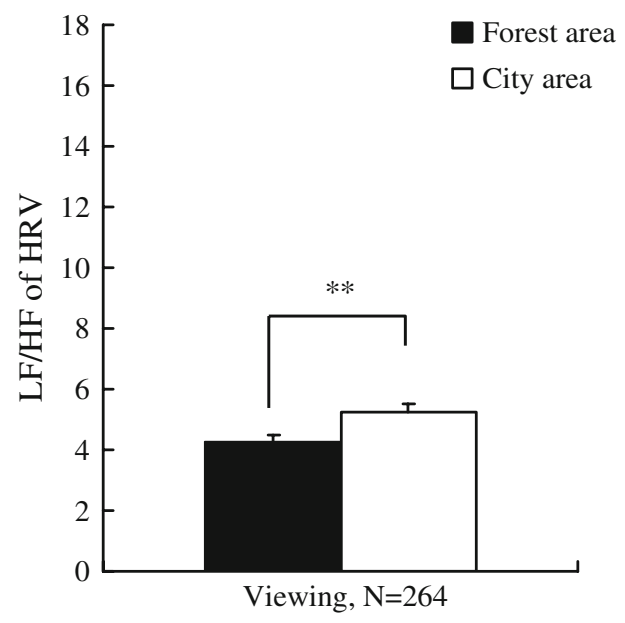

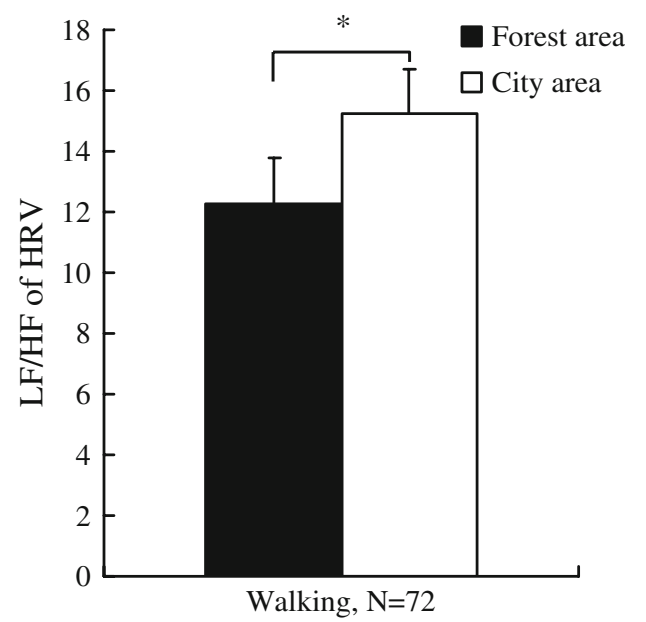

changes that indicate greater stress reduction than that afforded by walking in city surroundings.

From the perspective of physiological anthropology, human beings have lived in the natural environment for most of the 5 million years of their existence. Therefore, their physiological functions are most suited to natural settings [29]. This is the reason why the natural environment can enhance relaxation. The results of the physiological experiments conducted in this study yield convincing answers explaining the relationship between the natural environment and the relaxation effects in a human being (e.g., decrease in blood pressure and pulse rates, inhibition of sympathetic nervous activity, enhancement of parasympathetic nervous activity, and decrease in cortisol concentration levels in human beings).

The endocrine stress system comprises two broad components with considerable central anatomic interconnection, namely, the sympathetic adrenal-medullary (SAM) axis and the hypothalamic-pituitary-adrenal (HPA) axis [30]. The SAM axis is involved in immediate sympathetic activation preparing an individual to deal with a stressor, resulting in changes such as increased heart rate (HR) and blood pressure (BP) [31]. Cortisol is released by the HPA axis in response to stress [32]. While subjects viewed forest landscapes or walked around forest environments, their pulse rate, blood pressure, and cortisol concentration decreased. This suggests that both the main components of the endocrine stress system reacted in response to Shinrinyoku.

In particular, high cortisol levels can correspond to a low value of natural killer (NK) activity [33]. Further, cortisol concentration also holds great significance in terms of human immunological activity. Furthermore, the study of Li et al. [34-36] reported that forest surroundings could aid in the recovery of the human immune system, as determined from the perspective of NK activity.

For this reason, it can be suggested that not only forest environments but also other natural settings such as watersides or grasslands could promote relaxation in human beings. No evidence from field experiments conducted on other natural environments are available; however, Laumann et al. [28] have reported that, when subjects 
viewed natural environment through videos, including those of waterside scenes, they had a longer cardiac interbeat interval and lower heart rate, measured as the difference from the baseline, compared with subjects who viewed urban environment through videos.

All the indices were generally in excellent agreement with each other, implying that the forest environment possessed relaxing and stress-relieving effects. Our results also corroborate widely held beliefs that forest surroundings aid the physical relaxation of urban dwellers. In addition, these results suggest that physiological responses-pulse rate, blood pressure, salivary cortisol concentration, and $\mathrm{HRV}$ - can reflect the relaxing effects of forest environments.

\section{Psychological effects and relationship between psychological effects and physical environmental factors in ten forests across Japan}

The changes in the average POMS subscale scores after the viewing are presented in Fig. 8. Significant differences are seen between the changes resulting from viewing a forest landscape and those from viewing a city landscape. When subjects viewed a forest landscape, the POMS tension subscale score changed by -1.1 points, which is significantly lower than the change (3.5 points) after viewing a city landscape. The change in the POMS depression subscale score $(-0.3$ points) on viewing a forest landscape is also significantly lower than the score ( 0.1 points) on viewing a city landscape. There is a significant difference in the change in the POMS anger subscale score between viewing forest ( -0.2 points) and city landscapes (1.0 points). The change in the POMS fatigue subscale score ( -3.1 points) on viewing a forest landscape is significantly lower than the score (1.8 points) on viewing a city landscape. The change in the POMS confusion subscale score ( -1.0 points) on viewing a forest landscape is also significantly lower than that (1.8 points) on viewing a city landscape. However, the change in the POMS vigor subscale score (1.9 points) on viewing a forest landscape is significantly higher than that ( -1.9 points) on viewing a city landscape.

The changes in the average POMS subscale scores after walking are shown in Fig. 9. The results are the same as those for viewing. When walking, the changes in the average POMS subscales of tension (forest:-1.1 points, city: 3.2 points), depression (forest: -0.2 points, city: 0.8 points), anger (forest: -0.2 points, city: 0.8 points), fatigue (forest: -2.1 points, city: 1.3 points), and confusion (forest: -1.1 points, city: 1.1 points) are significantly different in the forest and city areas. And the change in the POMS vigor subscale score (4.2 points) on walking in forest settings is significantly higher than that ( -0.2 points) on walking in city settings.

The POMS measurements show that forest environments can relieve human psychological tension, depression, anger, fatigue, and confusion, and moreover, that they can enhance human psychological vigor. Furthermore, from the viewpoint of attention restorative theory (ART) [37], these results strongly support that the forest is a good restorative environment for human beings.

Kasetani et al. [38] reported that a relationship exists between the POMS score and the physical environmental factors (Fig. 10). The POMS anger subscale score and relative illumination had a significant correlation coefficient $(R=0.66)$ in the forest areas. Moreover, the POMS fatigue subscale score and relative humidity had a significant correlation coefficient $(R=0.70)$. Finally, the POMS

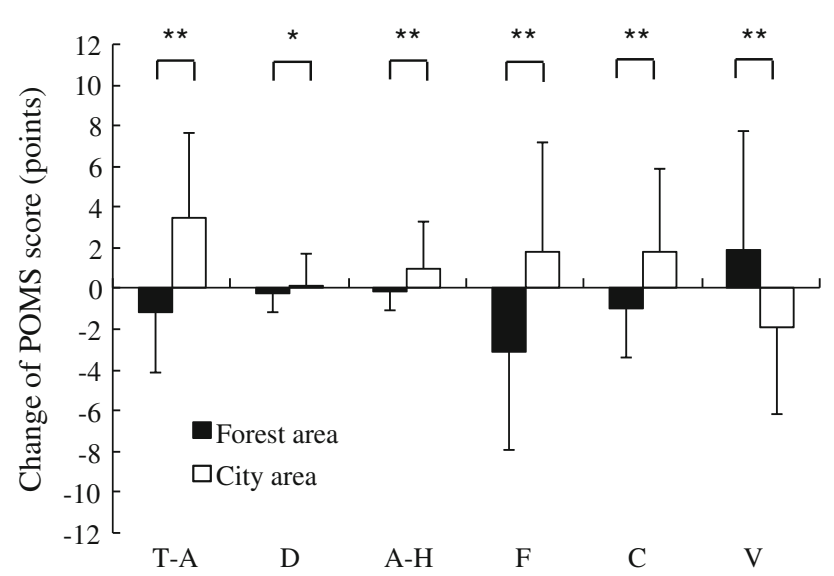

Fig. 8 Change in average POMS scores upon forest viewing. Mean $\pm \mathrm{SD} ; n=116$; ** $p<0.01$; $* p<0.05$; $p$ value by Wilcoxon signed-rank test. $T-A$ tension and anxiety, $D$ depression and dejection, $A-H$ anger and hostility, $F$ fatigue, $C$ confusion, $V$ vigor

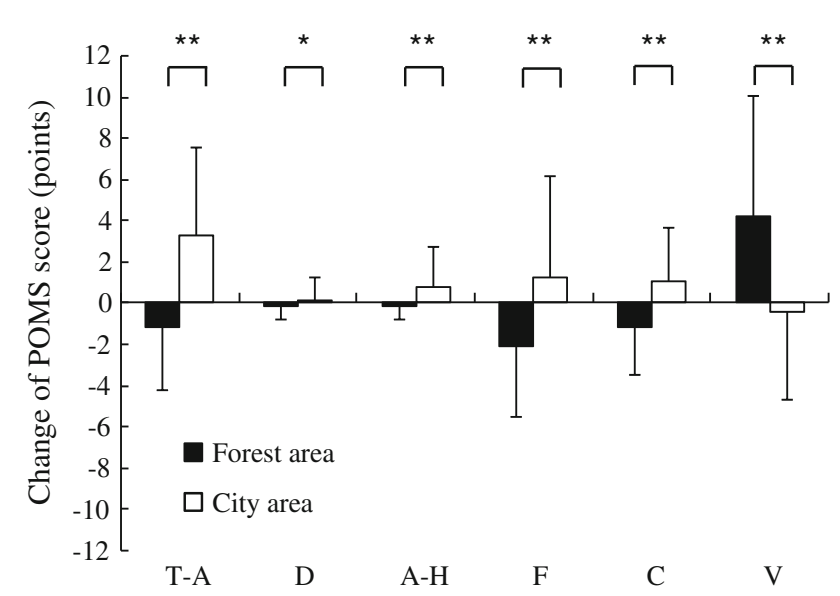

Fig. 9 Change in average POMS scores upon forest walking. Mean $\pm \mathrm{SD} ; n=78$; ** $p<0.01 ; p$ value by Wilcoxon signed-rank test. $T-A$ tension and anxiety, $D$ depression and dejection, $A-H$ anger and hostility, $F$ fatigue, $C$ confusion, and $V$ vigor 
Fig. 10 Relationship between POMS and physical environmental factors in forest area [38]
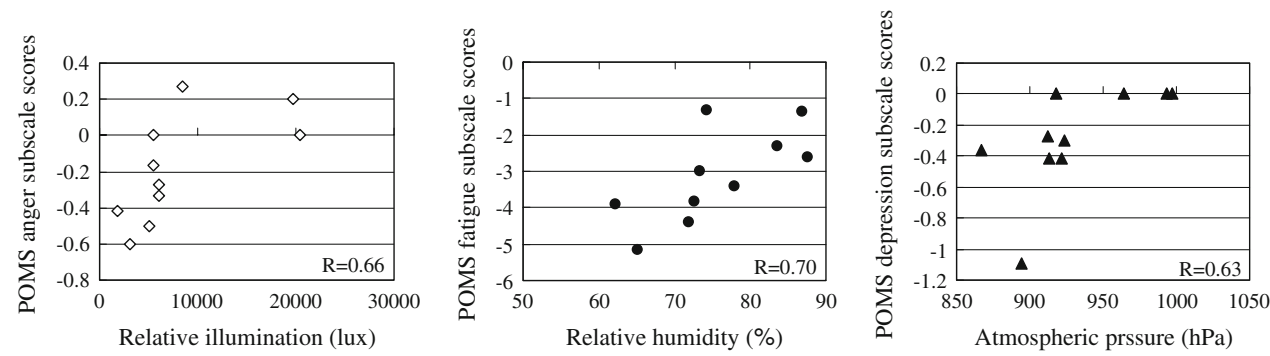

depression subscale score and atmospheric pressure had a significant correlation coefficient $(R=0.63)$.

When viewing a forest landscape, the low relative illumination reduces anger, and the low relative humidity lowers fatigue. Forests located at high elevations with low atmospheric pressure can reduce depression. We hope that these results can be used as basic guidelines in the design of therapeutic forest environments [39].

\section{Conclusion}

The results of studies performed on the physiological effects of Shinrin-yoku show that forest environments could lower concentrations of cortisol, lower pulse rate, lower blood pressure, increase parasympathetic nerve activity, and lower sympathetic nerve activity compared with city settings. The results of the physiological measurements suggest that Shinrin-yoku can aid in effectively relaxing the human body, and the psychological effects of forest areas have been correlated with the various physical environmental factors of forest. The studies of Shinrinyoku provide valuable insights into the relationship between forests and human health.

These results of Shinrin-yoku studies will contribute to support the development of a research field dedicated to forest medicine, which may be used to develop new strategies in preventive medicine. The results of the field experiments also provide a platform for interested enterprises, universities, and local governments to promote the effective use of forest resources in stress management, health promotion, rehabilitation, and the prevention of disease.

Acknowledgments This study was partly supported by a Grant-inAid for Scientific Research (S: 16107007) from The Ministry of Education, Culture, Sports, Science, and Technology (MEXT).

\section{References}

1. Ulrich RS, Simons RF, Losito BD, Fiorito E, Miles MA, Zelson $M$. Stress recovery during exposure to natural and urban environments. J Envir Psychol. 1991;11:201-30.
2. Frumkin H. Beyond toxicity: human health and the natural environment. Am J Prev Med. 2001;20(3):234-40.

3. Blood AJ, Zatorre RJ, Bermudez P, Evans AC. Emotional responses to pleasant and unpleasant music correlate with activity in paralimbic brain regions. Nat Neurosci. 1999;2:382-7.

4. Buchanan TW, Lutz K, Mirzazade S, Specht K, Shah NJ, Zilles $\mathrm{K}$, et al. Recognition of emotional prosody and verbal components of spoken language: an fMRI study. Cogn Brain Res. 2000;9:227-38.

5. Goel V, Dolan RJ. The functional anatomy of humor: segregating cognitive and affective components. Nat Neurosci. 2001;4:237-8.

6. Iidaka T, Omori M, Murata T, Kosaka H. Neural interaction of the amygdala with the prefrontal and temporal cortices in the processing of facial expressions as revealed by fMRI. J Cogn Neurosci. 2001;13:1035-47.

7. Herzog AM, Black KA, Fountaine DJ, Knotts TR. Reflection and attentional recovery as two distinctive benefits of restorative environments. J Environ Psychol. 1997;17:165-70.

8. Kaplan R. Wilderness perception and psychological benefits: an analysis of a continuing program. Leisure Sci. 1984;6(3):271-90.

9. Kaplan R. The nature of the view from home: psychological benefits. Environ Behav. 2001;33(4):507-42.

10. Kaplan S, Talbot JF. Psychological benefits of a wilderness experience. In: Altman I, Wohlwill JF, editors. Human behavior and the environment, vol 6 (Plenum Press, New York, 1983), pp. 163-203.

11. Kaplan S, Talbot JF. Psychological benefits of a wilderness experience. In: Altman I, Wohlwill JF, editors. Behavior and the Natural Environment. New York: Plenum Press; 1983. p. 163 203.

12. Talbot JF, Kaplan S. Perspective on wilderness: reexamining the value of extended wilderness experiences. J Environ Psychol. 1986;6(3):177-88.

13. Park BJ, Tsunetsugu Y, Kasetani T, Hirano H, Kagawa T, Sato $\mathrm{M}$, et al. Physiological effects of Shinrin-yoku (taking in the atmosphere of the forest): using salivary cortisol and cerebral activity as indicators. J Physiol Anthropol. 2007;26(2):123-8.

14. Editorial. Urban forest for human health and wellbeing. Urban Forestry \& Urban Greening. 2007;6:195-7.

15. Park BJ, Ishii H, Furuhashi S, Lee YS, Tsunetsugu Y, Morikawa $\mathrm{T}$, et al. Physiological effects of Shinrin-yoku (taking in the atmosphere of the forest): (1) 1) using HRV as indicator (in Japanese). Kanto J For Res. 2006;57:33-4.

16. Park BJ, Lee YS, Ishii H, Kasetani T, Toko A, Morikawa T, et al. Physiological effects of Shinrin-yoku (taking in the atmosphere of the forest): (2) using salivary cortisol and s-IgA as indicators (in Japanese). Kanto J For Res. 2006;57:37-8.

17. Park BJ, Tsunetsugu Y, Ishii H, Furuhashi S, Hirano H, Kagawa $\mathrm{T}$, et al. Physiological effects of Shinrin-yoku (taking in the atmosphere of the forest) in a mixed forest in Shinano Town, Japan. Scand J For Res. 2008;23:278-83.

18. Tsunetsugu Y, Park BJ, Ishii H, Fruhashi S, Lee YS, Morikawa T, et al. Physiological effects of Shinrin-yoku (taking in the 
atmosphere of the forest): (1) 2) using salivary cortisol and s-IgA as indicators (in Japanese). Kanto J For Res. 2006;57:35-6.

19. Tsunetsugu $Y$, Park BJ, Ishii $H$, Hirano H, Kagawa T, Miyazaki Y. Physiological effects of Shinrin-yoku (taking in the atmosphere of the forest) in an old-growth broadleaf forest in Yamagata prefecture, Japan. J Physiol Anthropol. 2007;26(2): 135-42.

20. Task Force of the European Society of Cardiology, the North American Society of Pacing, Electrophysiology. Heart rate variability: standards of measurement, physiological interpretation and clinical use. Circulation. 1996;93(5):1043-65.

21. Ohtomo N, Terachi S, Tanaka Y, Tokiwano K, Kaneko N. New method of time series analysis and its application to Wolf's sunspot number data. Jpn J Appl Phys. 1994;33:2821-31.

22. Cacioppo JT, Berntson GG, Binkley PF, Quigley KS, Uchino BN, Fieldstone A. Autonomic cardiac control II Noninvasive indices and basal response as revealed by autonomic blockades. Psychophysiology. 1994;31(6):586-98.

23. Weise F, Heydenreich F. Effects of modified respiratory rhythm on heart rate variability during active orthostatic load. Biomedica Biochimica Acta. 1989;48(8):549-56.

24. Yokoyama K, Araki S, Kawakami N, Takeshita T. Production of the Japanese edition of profile of mood states (POMS): assessment of reliability and validity (in Japanese). Jpn J Public Health. 1990;37(11):913-8.

25. Ohtsuka Y, Yabunaka N, Takayama S. Shinrin-yoku (forest-air bathing and walking) effectively decreases blood glucose levels in diabetic patients. Int J Biometeorol. 1998;41:125-7.

26. Ulrich RS. Natural versus urban scenes: some psycho-physiological effects. Environ Behav. 1981;13:523-56.

27. Hartig T, Evans GW, Jamner LD, Davis DS, Garling T. Tracking restoration in natural and urban field settings. J Environ Psychol. 2003;23(2):109-23.

28. Laumann K, Garling T, Stormark KM. Selective attention and heart rate responses to natural and urban environments. J Environ Psychol. 2003;23(2):125-34.

29. Miyazaki Y, Morikawa T, Hatakeyama E. Nature and comfort. In: Proceeding of 6th International Congress of Physiological Anthropology 2002; p 20.

30. Dinan TG. Stress and the genesis of diabetes mellitus in schizophrenia. Br J Psychiatry. 2004;184:s72-5.
31. Vente WD, Olff M, Amsterdam JGCV, Kamphuis JH, Emmelkamp PMG. Physiological differences between burnout patients and healthy controls: blood pressure, heart rate, and cortisol responses. Occup Environ Med. 2003;60:154-61.

32. Seplaki CL, Goldman N, Weinstein M, Lin YH. How are biomarkers related to physical and mental well-being? J Gerontol Biol Sci Med Sci. 2004;59:B201-B201.

33. De Amici D, Gasparoni A, Chirico G, Ceriana P, Bartoli A, Ramajoli I, et al. Natural killer cell activity and delivery: possible influence of cortisol and anesthetic agents. A study on newborn cord blood. Biol Neonate. 2000;78(1):70-2.

34. Li Q, Morimoto K, Nakadai A, Inagaki H, Katsumata M, Shimizu $\mathrm{T}$, et al. Forest bathing enhances human natural killer activity and expression of anti-cancer proteins. Int J Immunopathol Pharmacol. 2007;20(2):3-8.

35. Li Q, Morimoto K, Kobayashi M, Inagaki H, Katsumata M, Hirata $\mathrm{Y}$, et al. A forest bathing trip increases human natural killer activity and expression of anti-cancer proteins in female subjects. J Biol Regul Homeost Agents. 2008;22(1):45-55.

36. Li Q, Morimoto $\mathrm{K}$, Kobayashi M, Inagaki $\mathrm{H}$, Katsumata $\mathrm{M}$, Hirata $\mathrm{Y}$, et al. Visiting a forest, but not a city, increases human natural killer activity and expression of anti-cancer proteins. Int $\mathbf{J}$ Immunopathol Pharmacol. 2008;21(1):117-27.

37. Kaplan R, Kaplan S. The Experience of Nature: A Psychological Perspective. New York: Cambridge University Press; 1989.

38. Kasetani T, Takayama N, Park BJ, Furuya K, Kagawa T, Miyazaki Y. Relation between light/thermal environment in the forest walking road and subjective estimations for taking in the atmosphere of the forest (in Japanese). J Jpn Inst Lands Archit. 2008;71(5):713-6.

39. Gesler W. Therapeutic landscapes: theory and case study of Epidauros, Greece. Environ Plan D Soc Space. 1993;11:171-89.

40. Furuhashi S, Park BJ, Tsunetsugu Y, Hirano H, Kagawa T, Miyazaki Y. Physiological evaluation of the effects of Shinrinyoku (taking in the atmosphere of the forest) in Kayanodaira Highland, Kijimadaira Village, Nagano Prefecture (in Japanese). Kanto J For Res. 2007;58:219-22.

41. Yamaguchi M, Deguchi M, Miyazaki Y. The effects of exercise in forest and urban environments on sympathetic nervous activity of normal young adults. J Int Med Res. 2006;34:152-9. 